$$
\begin{array}{r}
\text { https://doi.org/10.52696/AIDE2513 } \\
\text { Reprints and permission: } \\
\text { The Malaysian English Language Teaching Association } \\
\text { Corresponding Author: }
\end{array}
$$

Kristof Savski kristof.s@psu.ac.th

\title{
CEFR as Language Policy: Opportunities and Challenges for Local Agency in a Global Era
}

\author{
Kristof Savski \\ Faculty of Liberal Arts \\ Prince of Songkla University, Thailand
}

\begin{abstract}
The Common European Framework of Reference for Languages (CEFR) has become one of the most widely cited documents in language education across the globe, its influence now felt far beyond the confines of Europe, the context for which it was originally produced. In Malaysia, CEFR was given particular prominence in the Malaysia Education Blueprint 2013-2025 and English Language Education Reform in Malaysia: The Roadmap 2015-2025, both of which positioned the framework as the primary yardstick by which curricula were to be developed and against which achievements (or lack thereof) were to be evaluated. This paper examines CEFR from the perspective of language policy, focussing particularly on the implications this document has for local agency in the Malaysian context. The paper begins by examining the constructs of language and language education underlying CEFR, pointing in particular to how these reflect the socio-political context for which the framework was developed. The next section examines how policy texts in the Malaysian context, in particular the 2015 Roadmap, have interpreted CEFR, highlighting in particular the way that these texts (as other policies across the globe) have tended to treat the CEFR reference levels as a global standard, with little scope for local agency. The final section considers alternative, localized models for using CEFR as language policy in Malaysia, in particular how the framework may be used in support of an inclusive agenda in which diversity and multilingualism are embraced.
\end{abstract}

\section{KEYWORDS: language policy, CEFR, teacher agency, localization}




\section{Introduction}

The Common European Framework of Reference for Languages (CEFR) has become one of the most widely used language policy documents over the last two decades. Starting, as its name suggests, as an instrument primarily aimed at the European context, the framework has spread far beyond the borders of that continent and become a feature of local language policy across a number of states (Byram \& Parmenter, 2012). It has had a particular impact in Asia, where it has seen use by nations like Japan, China, Taiwan, Vietnam, Thailand - and Malaysia (Franz \& Teo, 2017; Read, 2019; Author, 2019a, b, 2020). Key to the global spread of the framework is its purported universality, which is supposed to facilitate rapid, easy transferability of local qualifications between otherwise differing educational systems. Another source of popularity has been the widespread use of CEFR as a common point of reference for global testing (e.g. allowing neutral comparisons between IELTS and TOEFL) and global textbooks (e.g. allowing neutral comparisons between textbooks in a single series and their mapping to particular bands on global tests). In a globalized world characterised by intense exchange of people, knowledge, products and resources, being seen as universal point of reference has likely contributed to the popularity of CEFR.

A potential drawback of the search for global universality is that it may, when taken too far, compromise the agency of local actors in language policy, from those at the top level (government policymakers) to those at the grass roots (teachers). The key issue is that in order to achieve maximum universality, any large-scale global framework like CEFR must be minimally flexible, since significant variation between how it is interpreted and used may endanger its universality. This is at odds with the general need for policy of any kind to be open-ended enough to allow local actors an appropriate amount of leeway to take decisions based on their knowledge of the context in which they are working. Such flexibility is particularly key when it comes to language education policy at the global scale, since there are significant differences between different language ecologies and between the practical conditions individual educational actors have to consider when making decisions.

The purpose of this paper is to critically examine current uses of CEFR in Malaysian language policy from the perspective of local agency. I begin by introducing CEFR as a policy instrument, focussing especially on the conditions that motivated its development and on the key features of the orientation to language education that the framework is based on. The next section examines the way CEFR has been interpreted in recent Malaysian language policy texts, focussing particularly on how opportunities that the framework provides for local agency have been exploited. Finally, I highlight several overarching questions regarding how CEFR can be interpreted in light of Malaysia's language ecology, hoping to stimulate thought about how local conditions could be given a more prominent place in planning education according to global frameworks.

\section{CEFR, its Origins and its Ideas}

While CEFR was first published in 2001, its history is significantly longer than the roughly two decades that have elapsed since then. Its beginnings can be traced back to the 1960s, when descriptions of language proficiency began to be developed at the parent institution of CEFR, the 
Council of Europe. This body, whose commitment to language policy issues is part of a broader focus on social cohesion, was at the time responding to a relatively clear set of practical issues in language education. These were related primarily to the increasingly close social, cultural and particularly economic ties among Western European nations, furthered by the establishment of the European Economic Community in 1967. While much of this integration revolved around facilitating exchange of resources and products between member states, it also involved the loosening of restrictions around migration. This was of particular value to more developed nations in Northern Europe, whose post-war redevelopment was often hampered by a lack of domestic workforce and who thus stood to benefit from immigration from other, less developed parts of Europe. Likewise, such population movement was desirable for southern European nations like Italy, Spain and Portugal, whose continued economic issues led to high rates of unemployment and welfare-dependency.

It is from considering the need for such migrant workers to be integrated in a new society that the earliest precursor of CEFR was developed. Threshold, which now broadly equates to level B1 on CEFR, aimed to provide an account of the minimal linguistic competences a migrant worker would need to function in a context where his/her first language was not the dominant language of communication (e.g. an L1 speaker of Italian working in Germany). As this was mainly aimed at blue-collar migrants, the situations described largely pertained to survival situations (e.g. shopping, travel, simple official matters) and general literacy (e.g. getting the gist of straightforward texts like immigration forms), thus generally not touching upon, for instance, the kind of literacy skills needed for office jobs or for higher education. Threshold was presented as a unitary description and thus did not present any of these competences scaled according to difficulty, as CEFR did later. Indeed, as Threshold offered no path for learners to follow in order to arrive at the target competence, it was noted by its authors that its demands on language learners "may appear to be very formidable indeed" (Van Ek \& Trim, 1990, p. 9). This blind spot was addressed in subsequent years with the development of new descriptions, first of lower proficiency levels with Waystage (A2) and Breakthrough (A1), and later of higher (academic) proficiency with Vantage (B2). Two more levels of higher proficiency ( $\mathrm{C} 1$ and $\mathrm{C} 2$ ) were added during the development of CEFR in the late 1990s, when all these descriptions of individual levels were redeveloped into now familiar sets of thematically-organized six-level scales.

As these scales have become the most often referred to part of CEFR (see for instance the policies discussed below), it is important to understand the process through which they were created. As has been remarked elsewhere (e.g. Hulstijn, 2007; Wisniewski, 2018), the scales were not developed on the basis of any particular theoretical model of language acquisition, nor do they explicitly follow any approach to language teaching. Rather, they were developed by pooling existing resources (Threshold and numerous others, including testing standards, textbooks, etc.) for descriptors of various kinds of specific language abilities. Through a succession of workshops conducted with foreign language teachers in Switzerland, these descriptors were then organized thematically, according to particular sets of skills they referred to (e.g. 'Writing correspondence'), and according to difficulty, with statistical calculations (Rasch modelling) used to identify boundaries between the six reference levels (for a detailed account, see North, 2000). Thus, the CEFR reference levels represent "scaled teacher perceptions" of language learners' development, not a theoretically-elaborated model of second language learning (North, 2014, p. 23). 
While the resultant six levels have been the most cited part of CEFR, the framework consists of much more than these reference levels. Indeed, it may be argued that the descriptive scheme offered by the reference levels is merely a minor part of the overall package that CEFR represents, key to which is a holistic philosophy of language education policy and practice. A key element of this philosophy is the use of sociolinguistic analysis to describe the needs of prospective speakers of any given language in particular contexts and the resultant articulation of learning objectives according to specific actions that the analysis identifies as crucial to learners' needs. The resultant focus on actions, encoded in the framework's recognizable "can do" statements, is what differentiates this approach from those in the past, namely that it puts focus on the end product of learning (communicative action), not the individual building blocks of language (grammar, words) that may be needed to arrive at it (Piccardo \& North, 2019). In pursuing such a philosophy, CEFR and its precursors are not unique, but rather reflect ongoing paradigm shifts in language education. There was much overlap between the development of documents like Threshold and early models of communicative language teaching (CLT), with the same broad philosophy shared by both (Trim, 2012).

Though this parallel early development led to many similarities between how competence in a second language was conceptualized by CLT and CEFR, these understandings have since drifted somewhat apart. Namely, while the focus of early CLT on communicative actions has been tempered by a resurgence of the form-focussed grammatical syllabus, particularly in what may be termed "commercial CLT" (i.e. that promoted by global ELT textbooks), the understanding of communicative competence that CEFR promotes has sought to evolve toward a dynamic, actionoriented vision in line with how contemporary perspectives in applied linguistics have put into question the view of a unitary, monolingual communicative competence (Canagarajah, 2018; Li, 2018). This is particularly clear when comparing the 2001 version of CEFR, whose somewhat rigid descriptions and apparent lack of tolerance for dynamicity and fluidity drew much criticism (Leung, 2013; Shohamy, 2011), to the recently published Companion Volume (Council of Europe, 2018), in which attempts have been made to move toward taking greater account of the complexity that characterises how multilingual speakers enter into communication. This was chiefly achieved through the addition of new scales to describe how users can pool resources from different languages to achieve their communicative purpose (plurilingual competence), how adept they are at crossing the boundaries of cultures (pluricultural competence) and how well they are able to aid others to communicate across the borders of languages and cultures (mediation competence). Accompanying literature has also attempted to position the descriptions provided by CEFR in light of a more holistic conceptualization of language education, the Action-oriented Approach, which attempts to articulate a more dynamic, fluid and changing vision of communicative competence (Piccardo \& North, 2019). While these moves may be seen as being somewhat restricted by the continued reliance on the existing construct (Deygers, in press), they do reflect an attempt to move CEFR forward with contemporary theory in applied linguistics.

\section{CEFR and Universality in Malaysian Language Policies}

This section briefly discusses how CEFR has thus far been integrated in language policy in Malaysia. It does soon the basis of research conducted in 2017-19 with the aim of describing how 
the key tenets of the framework were interpreted as it was transferred to the Thai and Malaysian policy contexts. The study involved a critical discourse analysis of documents from both contexts, focussing in particular on identifying what elements of CEFR were being transferred and what concepts these elements were linked with (for a more detailed account, see Author, 2019b). The data were three policy texts, a general education strategy (Malaysia Education Blueprint 2013-25) and two strategies for English language education policy (English Language Education in Malaysia: An Agenda for Reform 2015-25 and English Language Education Reform in Malaysia: The Roadmap 2015-25). Among these, significant differences exist, since while Blueprint makes reference to CEFR when setting overarching goals, its broader focus means that it provides less detail with regard to individual areas of education when compared to the two more specific policy texts, Agenda and Roadmap. At the same time, there are also many parallels, relating especially to the ubiquitous use of transnational comparisons in all three texts. In Blueprint, comparisons between Malaysia and other educational contexts are mainly made on the basis of instruments like PISA and TIMSS, which assess educational success or failure in broad terms (e.g. in terms of critical literacy and maths). When such comparisons are made with regard to Malaysian students' English proficiency in Agenda and Roadmap, CEFR tends to act as the frame of reference through which they are expressed:

According to the Results Report Cambridge Baseline 2013 [...], Malaysian English learners on average reach A1 by Year 6, and A2 by Form 3; they are still on average at A2 in Form 5, but the average is moving up to B1 by Form 6. A comparison with other countries using Cambridge Examination results [...] puts Malaysia ahead of Thailand, Myanmar, Indonesia and India, with substantially more evidence of B1 and higher, but behind a country like Brazil. However, European countries typically set B2 as the target on exit from secondary education, although this is actually reached only in Northern Europe [...]. This confirms the expected situation, namely that the existing English language programme is adequate for traditional domestic purposes, but that we have to move up a level if we are to take our place among the advanced nations of the world. (Agenda, p. 18)

This extract exemplifies in very explicit terms the kind of discourse that transnational comparisons of educational success tend to generate (see e.g. Takayama, 2008; Waldow et al., 2014). Aside from a general diagnosis of current levels of domestic achievement (e.g. 'A2 by Form 3'), the text constructs a virtual 'league table' in which Malaysia is compared to other nations. Among these, what is worth pointing out is the foregrounding of regional competitors like Thailand and Indonesia and, in particular, the idealization of particular contexts - in this case, the rather vaguely identified 'European countries' and 'Northern Europe'. Despite its vagueness, such idealization of particular educational systems, often on the basis of stereotypes, is common in the kind of discourse that develops around transnational comparisons (Takayama, 2008). In such a competition-oriented discourse, the perceived superiority of such idealized contexts is then used to justify long-term goals, here by explicitly referring to the aspiration of Malaysia to achieve the status of an 'advanced nation'.

What must be considered in the present discussion is the rigid interpretation of CEFR that this discourse promotes. Through such comparisons, CEFR is likened to quantitative instruments like PISA, and to global English tests like IELTS, all of which are characterised by distance from any particular local context (being universally applied across the globe and administered by an 
external, purportedly neutral body like the OECD, British Council, or Cambridge), and the resultant lack of agency that local actors have in relation to them. Such a view appears particularly relevant to how CEFR is understood in Agenda and Roadmap:

Any country or other body that makes use of the CEFR is free to take as much or as little from it as is desired. But as in the case of the metric system, it makes sense to adopt the system as a whole. For example, in adopting the metric system, it would be possible - but pointless and foolish - to adopt metric weights but retain imperial miles and furlongs for distances. (Roadmap, p. 62)

This extract makes use of a metaphor to frame CEFR in a particularly salient way, establishing parallels to different systems of measurements and making an unfavourable comparison between the partial adoption of CEFR and the partial adoption of a system of measurements. Such a comparison is based on a set of presuppositions, as with all metaphors (Semino, 2008), regarding the properties of both domains which are being compared, language education policy (target domain) and physical measurement systems (source domain). Through this comparison and the accompanying assessments ('makes sense', 'pointless and foolish'), language education policy is implicitly portrayed as a domain where objective measurement is desired, where competing means of measurement are available (CEFR being one) and where such instruments are of a predetermined, inflexible nature (as is the case with physical measurement as a field). This kind of discourse positions CEFR as a universal system of measurement, one which local actors must adopt as a whole, in order to avoid disturbing its unquestioned internal logic, and over which they, implicitly, have no agency.

The point that must be highlighted here is that such a reading of CEFR, which is by far not unique to the Malaysian context and indeed represents the dominant manner in which the framework is interpreted, is highly problematic when considering its design. CEFR was not by any means intended to be used as an instrument for discrete measurement, since it neither contains a complete inventory of the features of communicative competence nor does it allow for their straightforward quantification. Rather, CEFR provides users with a number of scales containing textual descriptors, which can then be used as a heuristic to estimate a particular learner's existing level of ability and/or to make decisions regarding future learning goals. With such use in mind, the descriptors that the framework provides are generally worded in a relatively open-ended manner despite their relatively clear structure (with particular actions at the core), allowing for users to interpret their precise meaning according to the needs of a particular local context. Consider, for instance:

Can recognise significant points in straightforward newspaper articles on familiar subjects.

Can understand most factual information that he/she is likely to come across on familiar subjects of interest, provided he/she has sufficient time for re-reading.

Can understand the main points in descriptive notes such as those on museum exhibits and explanatory boards in exhibitions (Council of Europe, 2018, p. 63). 
These descriptors are provided at level B1 in the scale entitled 'Reading for Information and Argument' and contain various open-ended elements, particularly those used to describe the qualities of input text (What constitutes 'straightforward' or 'descriptive' text?), the ability of the speaker (What points in a text are 'significant'?), the range of potential areas (What topics are 'familiar'?) as we as conditions (How much time for re-reading is 'sufficient'?). This feature of CEFR has created issues in language testing, where such openness, or rather vagueness, can make the identification of a clear CEFR-aligned construct difficult (Alderson et al., 2006), and has led to significant disparities between tests nominally aimed at the same level (Deygers et al., 2018). This is compounded by the inherent incompleteness of CEFR, since the framework does not provide (and does not claim to provide) all-encompassing descriptions of proficiency at particular levels. The descriptors presented above, for instance, are not intended to catalogue the entire scope of abilities relevant to 'Reading for Argument and Information' at B1. Rather than constituting a list of everything a speaker at a particular level needs to be able to do, the descriptors provided are simply intended to provide examples of what a speaker of a particular proficiency is likely to be able to do. It is up to the users of CEFR to make these vague examples more specific and concrete by considering the context in which they are to be used. In the above case, we would for instance need to decide whether a text on the history of Penang, taken from a brochure handed out to tourists, would fall within the scope of 'familiar topics' of a particular set of speakers, and whether this genre is similar enough to those mentioned above (in particular 'descriptive notes [at] museum exhibits'). In some cases, we may thus also need to disregard particular descriptors if they are unsuited to a particular context, or to expand the descriptions provided with more information. Such flexibility is built into CEFR, but grass-roots actors like teachers must be provided sufficient agentive opportunities to take advantage of it.

\section{What Counts as 'Can Do' in a Glocal Malaysia?}

Having examined how the rigid interpretation of CEFR in Malaysian language policy departs from its flexible design, I now move to a broader discussion of some of the reasons why the framework needs to be re-interpreted according to local conditions in Malaysia. The reason why this question merits more attention stems from the differences between the sociolinguistic contexts of language education in Malaysia from that in Europe, where the framework was developed.

While, as I discuss above, the manner in which CEFR levels describe the development of language proficiency does not draw on any particular theory in second language acquisition, it does reflect certain assumptions regarding how acquisition of an L2 takes place in a particular sociolinguistic context. Much of CEFR appears to rest on the broad assumption that the L2 does not have any significant local role in the language ecology where the teaching/learning takes place, rather taking the role of a stereotypical 'foreign' language to which learners are primarily exposed through planned classroom instruction. The lowest CEFR reference levels (A1 and A2) reflect this, as they primarily describe the ability to perform the kinds of communicative tasks associated with everyday life (e.g. establishing social contact, asking for and providing personal information, etc.) that those learning a foreign language from scratch would have little familiarity with. Proficiency in performing such actions culminates at B1, which describes the "ability to maintain interaction and get across what you want to" as well as "to cope flexibly with problems in everyday life" (Council of Europe, 2001, p. 34), primarily in the context of a society where the L2 is the dominant 
language (e.g. an L1 speaker of Italian using German as an L2 in Germany). As discussed above, this reflects the history behind CEFR - B1 is the successor to Threshold and reflects its focus on describing the abilities needed to live and perform certain types of work as an immigrant. Above this level, CEFR descriptions begin to change, moving away from the previous focus on 'everyday' tasks and toward a more academic proficiency. Much of levels B2, C1 and C2 describe the kind of advanced literacy that is necessary either for the performance of more complex white-collar work (e.g. certain aspects of business administration) or for higher study in an L2-dominant environment. These levels are thus a reflection of the growing need in European education, particularly at the tertiary level, for a common point of reference regarding minimum entry requirements for students transferring from other educational systems (Deygers et al., 2018).

A number of points of potential incompatibility may be found between this idealized progression in L2 competence and the context of English language education in Malaysia. The most obvious of these is that, for a significant proportion of the population of Malaysia, English does play much more of a role in everyday life than would be the case in most of continental Europe. Though a straightforward Kachruvian categorization of Malaysia into the 'outer circle' can be disputed, both owing to local pushes toward the promotion of Bahasa Malaysia (Gill, 2014) as well as the inherently oversimplied nature of such broad global categories, there can be little arguing with the observation that English is a local language, not simply a foreign one, in the Malaysian context. While Bahasa Malaysia is the official national language, English plays a prominent role in public and private communication, particularly in urban centres, and is - in combination with other languages - an indispensable element of the linguistic repertoire of many Malaysians (see e.g. Albury, 2020; Coluzzi, 2017; Pillai \& Ong, 2018). It is thus acquired not only through planned instruction but, to a significant extent, through exposure to authentic communication. This is a pattern of acquisition which is not characteristic of the 'English as a foreign language' ecology which acted as the primary point of reference for the developers of CEFR at the Council of Europe and for the Swiss language teachers whose perceptions were surveyed in the development of the CEFR reference levels (see above). While this disparity does not make CEFR unusable in the Malaysian context, it does point to the need for further thought on localizing the framework.

One area that such localization may focus on is the question of how to accommodate the presence of different Englishes in the language ecology of Malaysia, and indeed the importance of these Englishes in the language repertoires of Malaysians. An L2 user's contact with language variation is considered in CEFR, but only to a minimal extent, and once again from the perspective of 'foreign language' education, as learners are simply assumed to only have contact with the standard language until around $\mathrm{C} 1$, when users are, for instance, described as being able to understand an "unfamiliar" accent if they are able to "confirm occasional details" (Council of Europe, 2001, p. 66). In such a framework, there is thus little accounting for a situation where users of English are very likely to come into contact with and acquire, to varying degrees, linguistic resources associated with a basilect ('Malaysian Colloquial English') and those of an acrolect ('Standard English'), as well as social conventions regarding how these resources may be deployed in particular social situations (Pillai \& Ong, 2018). In contrast to a 'foreign language' environment, where use of the standard language in the classroom is targeted, it is the ability of an individual to flexibly adapt their use of Englishes to social context that may be considered as a standard of proficiency in Malaysia and in other ecologies with similar characteristics. 
In order to foster competitiveness on the global stage, a key challenge for education in an outwardlooking nation with as diverse a language ecology as Malaysia is how to harness the competences that individuals acquire through their socialization into the local society to achieve success outside that context. Acknowledging local diversity and making use of it is key, particularly because diversity is what globally mobile Malaysians are likely to encounter when, for instance, engaging in use of English as a lingua franca. As has been demonstrated by research on this phenomenon, success in intercultural communication in English among speakers who do not share the same first language is more likely if interlocutors cooperate to construct meaning, adapt their own language use, anticipate and address others' lack of understanding, etc. (Baker, 2017). Much of this rests on whether interlocutors are, on the one hand, aware of the diversity of Englishes in the modern world, and, on the other hand, willing to adapt themselves to others (ibid.). For contemporary English language education, a key challenge is thus how to develop speakers with an awareness of and a positive attitude toward different Englishes (Tupas, in press) and toward different cultures (Byram, 1997). The fact that Malaysian students, through growing up in a complex and diverse society, will hopefully already have had to opportunity to acquire such a positive disposition provides them with a significant competitive advantage over others. An approach to language education which finds a way to balance such local potential with global frameworks like CEFR is vital to achieving such a goal.

\section{Outlook}

In this article, I have examined the challenges and opportunities that CEFR, as a global framework, presents for local agency, focussing specifically on English language education in the Malaysian context. My main observation has been that CEFR has thus far been interpreted in a rigid way in Malaysian language policy texts, a reading which, while conforming to how the framework tends to be interpreted across the world, is at odds with its design and is thus unlikely to extract the maximum potential from it when it comes to local agency. Instead, I have argued that a more proactive way of reading the framework would be advantageous, in particular given the many differences between the role of English in the language ecology in which CEFR was developed and that of Malaysia.

Such conceptual pro-activity may be transferred into concrete practices in different ways. In other contexts, it has involved the development of localized versions of CEFR, such as CEFR-J in Japan and FRELE-TH in Thailand, which have attempted to modify the descriptions in the framework. Up until now, these modifications have been rather minimal (largely involving the addition of more levels, e.g. A1.1, A1.2 and A1.3 in CEFR-J), but there is little to stop policymakers from reconceptualising some of the elements of CEFR to a larger extent. As future plans for a 'CEFRM' are mentioned in Roadmap, there appears to be a window of opportunity to develop framework whose descriptions broadly stay within the spirit of those developed by the Council of Europe but also take greater account of the specific place English has in Malaysia.

There is also an urgent need to educate teachers about how they can best make use of CEFR, given that the scale of the framework can be quite overwhelming, despite the efforts of its developers to make it accessible. Teachers need to be taught how to decode the language of CEFR, how to make use of it for diagnostics and for objective-setting, and, most crucially, how to think beyond the partial descriptions of competence that CEFR offers and exercise their own agency when working 
with the framework. By developing such 'CEFR literacy' at the grass-roots, a positive groundwork can be laid to facilitate future uses of a locally developed framework, thus enabling the kind of holistic, learner-centred reform of English language education sought after in Malaysia.

\section{References}

Albury, N. (2020). Beyond economy and culture: language-in-education preferences of Malaysian youth. Current Issues in Language Planning, 21 (3), 301-319. https://doi.org/10.1080/14664208.2019.1680161

Alderson, J. C., Figueras, N., Kuijper, H., Nold, G., Takala, S. \& Tardieu, C. (2006). Analysing Tests of Reading and Listening in Relation to the Common European Framework of Reference: The Experience of The Dutch CEFR Construct Project. Language Assessment Quarterly, 3 (1), 3-30. https://doi.org/10.1207/s15434311laq0301_2

Baker, W. (2017). Culture and Identity through English as a Lingua Franca: rethinking concepts and goals in intercultural communication. Berlin: De Gruyter.

Byram, M. \& Parmenter, L. (Eds.) (2012). The Common European Framework of Reference: The Globalization of Language Education Policy. Bristol: Multilingual Matters.

Byram, M. (1997). Teaching and assessing intercultural communicative competence. Bristol: Multilingual Matters.

Canagarajah, S. (2018). Translingual Practice as Spatial Repertoires: Expanding the Paradigm beyond Structuralist Orientations. Applied Linguistics, 39 (1): 31-54. https://doi.org/10.1093/applin/amx041

Coluzzi, P. (2017). Language planning for Malay in Malaysia: A case of failure or success?. International Journal of the Sociology of Language (244), 17-38. https://doi.org/10.1515/ijsl-2016-0055

Council of Europe (2001). Common European Framework of Reference for Languages: learning, teaching, assessment.

Council of Europe (2018). Common European Framework of Reference For Languages: Learning, Teaching, Assessment: Companion Volume with New Descriptors.

Deygers, B. (in press). The CEFR companion volume: Between research-based policy and policy-based research. Applied Linguistics. https://doi.org/10.1093/applin/amz024

Deygers, B., Van Gorp, K., \& Demeester, T. (2018). The B2 level and the dream of a common standard. Language Assessment Quarterly, 15 (1), 44-58. https://doi.org/10.1080/15434303.2017.1421955

Franz, J., \& Teo, A. (2018). 'A2 is Normal' - Thai Secondary School English Teachers' Encounters with the CEFR. RELC Journal, 49 (3), 322-338. https://doi.org/10.1177/0033688217738816

Gill, S. K. (2014). Language Policy Challenges in Multi-Ethnic Malaysia. Amsterdam: Springer.

Hulstijn, J. H. (2007). The shaky ground beneath the CEFR: Quantitative and qualitative dimensions of language proficiency. The Modern Language Journal, 91 (4), 663-667. https://doi.org/10.1111/j.1540-4781.2007.00627_5.x

Leung, C. (2013). The "social" in English Language Teaching: abstracted norms versus situated enactments. Journal of English as a Lingua Franca, 2 (2), 283-313. https://doi.org/10.1515/jelf-2013-0016

Li, W. (2018). Translanguaging as a Practical Theory of Language. Applied Linguistics, 39 (1), 9-30. https://doi.org/10.1093/applin/amx039

North, B. (2000). The Development of a Common Framework Scale of Language Proficiency. Hamburg: Peter Lang.

North, B. (2014). The CEFR in Practice. Cambridge: Cambridge University Press.

Piccardo, E., \& North, B. (2019). The action-oriented approach: a dynamic vision of language education. Bristol: Multilingual Matters. 
Pillai, S., \& Ong, L. T. (2018). English(es) in Malaysia. Asian Englishes, 20 (2), 147-157. https://doi.org/10.1080/13488678.2018.1459073

Read, J. (2019). The influence of the Common European Framework of Reference (CEFR) in the Asia-Pacific region. LEARN Journal: Language Education and Acquisition Research Network, 12 (1), 12-18.

Semino, E. (2008). Metaphor in discourse. Cambridge: Cambridge University Press.

Shohamy, E. (2011). Assessing Multilingual Competencies: Adopting Construct Valid Assessment Policies. Modern Language Journal, 95 (3), 418-429. https://doi.org/10.1111/j.1540-4781.2011.01210.x

Takayama, K. (2008). The politics of international league tables: PISA in Japan's achievement crisis debate. Comparative Education, 44 (4), 387-407. https://doi.org/10.1080/03050060802481413

Trim, J. L. (2012). The Common European Framework of Reference for Languages and its Background: A Case Study of Cultural Politics and Educational Influences. In Byram, M. \& Parmenter, L. (eds.), The Common European Framework of Reference for Languages: The Globalisation of Language Education Policy (pp. 14-35). Bristol: Multilingual Matters.

Tupas, R. (in press). Fostering translingual dispositions against Unequal Englishes. English in Education. https://doi.org/10.1080/04250494.2020.1786367

Van Ek, J. A. \& Trim, J. (1990). Threshold 1990. Cambridge: Cambridge University Press.

Waldow, F., Takayama, K., \& Sung, Y. K. (2014). Rethinking the pattern of external policy referencing: Media discourses over the "Asian Tigers" PISA success in Australia, Germany and South Korea. Comparative Education, 50 (3), 302-321. https://doi.org/10.1080/03050068.2013.860704

Wisniewski, K. (2018). The empirical validity of the Common European Framework of Reference scales. an exemplary study for the vocabulary and fluency scales in a language testing context. Applied Linguistics, 39 (6), 933-959.

https://doi.org/10.1093/applin/amw057 